\title{
Pigmentocracies: Ethnicity, Race and Color in Latin America'
}

\author{
George Reid Andrews ${ }^{2}$ \\ Profesor e investigador de la Universidad de Pittsburgh, Pittsburgh, EE.UU. \\ reidı@pitt.edu
}

\section{Edward E. Telles and the Project on Race and Ethnicity in Latin America (PERLA). Pigmentocracies: Ethnicity, Race and Color in Latin America. Chapel Hill: University of North Carolina Press, 2014.}

Este libro se basa en encuestas realizadas en 2010, en cuatro países latinoamericanos: Brasil, Colombia, México y Perú. El aspecto más novedoso y original de las encuestas fue el uso de la "paleta de colores", un instrumento que permitió a los entrevistadores medir de manera consistente el color de la piel de los entrevistados, para después relacionar el color con las auto-identificaciones raciales (blanco, mestizo, indígena, negro, etc.) de las personas encuestadas. El gran hallazgo del libro es que, en todos los países, se encontró una fuerte correlación entre el color de la piel y los indicadores socioeconómicos de los individuos (por ejemplo, sus niveles de educación, de ingreso, de ocupación, etc.), una correlación más fuerte y consistente que la relación entre la identidad racial y aquellos indicadores. Quiere decir que el color de la piel tiene un papel más significativo que las identidades cotidianas en la producción y reproducción de las desigualdades raciales.

Considero este libro como una contribución sumamente importante y original al estudio de las desigualdades raciales en América Latina, por los siguientes motivos. Primero, en el libro me impresionó el modelo de la colaboración intelectual internacional. Los académicos hablamos de la necesidad de tales colaboraciones, pero no cumplimos tan frecuentemente con este principio tan valioso; y cuando sí intentamos las colaboraciones internacionales, son muy pocos los proyectos que combinan el rigor intelectual que se ve en este libro, con los niveles igualmente altos de compañerismo intelectual. Tuve la buena suerte de participar en dos de las reuniones del grupo PERLA, en que se presentaban los resultados preliminares de las muestras y los análisis realizados por los distintos equipos. Lo que presencié en esas reuniones fue un espíritu de fuerte compromiso con el proyecto global, junto con una disposición tanto para criticar como para recibir las críticas y utilizarlas para mejorar el producto final. Los integrantes también me contaron un poco del proceso de diseñar el proyecto y los cuestionarios nacionales, los cuales se prepararon con base en una visión común, pero también con pleno reconocimiento de las especificidades de cada país. Esto permitía que los resultados del proyecto fuesen tan útiles, tanto en el ámbito regional como en cada país.

1 Comentario presentado en el Seminario Internacional "Estadísticas étnico-raciales en Colombia y América Latina". Cali, Universidad del Valle, 20 de noviembre de 2014.

2 Magíster y Doctor en Historia. 
Ese enfoque, a la misma vez nacional y regional, ha permitido que se desarrollen en el libro dos diálogos que frecuentemente se invocan pero que no siempre se implementan.

El primero es el diálogo entre las experiencias históricas y actuales indígenas y las experiencias históricas y actuales afrodescendientes. En la década de 1960 Marvin Harris y Pierre van den Berghe ya reclamaban la necesidad de examinar estos dos grupos conjuntamente, y Peter Wade relanzó esa propuesta, de manera más sistemática, en la de $1990^{3}$. Los trabajos de aquellos autores provocaron alguna respuesta de parte de los historiadores y los antropólogos ${ }^{4}$; pero ahora, con el proyecto PERLA, tenemos informaciones y un cuadro analítico que permite la comparación directa de estos dos grupos y sus situaciones actuales en México, Colombia, Perú y, no tengo duda, en otros países en el futuro.

El otro diálogo promovido por PERLA es el diálogo entre Brasil y los países de Hispanoamérica. Creo que queda evidente que los estudios sobre las cuestiones de raza y, especialmente, las cuestiones raciales relacionadas específicamente con las poblaciones afrodescendientes, son mucho más desarrollados en Brasil que en cualquier otro país latinoamericano. Esto se explica por una serie de factores, incluso la larga historia de la movilización negra en el Brasil, compuesta de movimientos que reclamaban de sus intelectuales nacionales más y mejores estudios de los afrodescendientes, su protagonismo en la historia brasileña, y las condiciones actuales de desventaja en que vive la gran mayoría de la población negra de ese país.

Esas reclamaciones contribuyeron a que surgiera en las últimas décadas una gran ola de estudios sobre el pasado y el presente afrobrasileño. Esta proliferación de estudios mejoró en mucho nuestros conocimientos de aquel país; pero esos estudios también contribuyeron a formar la impresión, muy difundida, que los grandes lineamientos de la historia afrobrasileña definen los grandes lineamientos de la historia afrolatinoamericana en su sentido más general.

Esta postura en realidad no está completamente equivocada, por el solo hecho de que los afrobrasileños representan tres de cada cuatro afrolatinoamericanos. Cualquier fenómeno que afecta a ellos afecta a la gran mayoría de los afrodescendientes de la región. Pero al mismo tiempo, hay que reconocer que las experiencias hispanoamericanas no son reproducciones automáticas y directas de la experiencia brasileña. Los datos del proyecto PERLA nos muestran claramente que Brasil es un caso sui generis en varios sentidos, como por ejemplo en la correlación, mucho más fuerte en Brasil que en los países hispanos, entre las autoidentificaciones raciales de las personas y las identificaciones raciales de esos individuos hechos por los observadores ajenos. Parece que las categorías raciales son mucho más definidas y aceptadas en Brasil que en los países hispanos, un hallazgo importantísimo que muda simultáneamente nuestra visión de Brasil, de los países hispanos y de las identidades raciales en la región como un todo. Por revelar las características específicas de la situación racial en los cuatro países, los datos de PERLA nos permiten identificar y reconocer las especificidades no solo de Brasil, sino de los países hispanos también.

Este ejemplo de las identidades raciales me lleva a mi último punto. Los que estuvieron presentes en mi presentación sobre las categorías raciales en los censos quizás recuerdan mis observaciones sobre la inestabilidad y la mutabilidad de esas categorías, una observación que está ampliamente aceptada en la literatura académica. En vista de esa inestabilidad, ¿por qué utilizar datos estadísticos tan cuestionables? Utilizamos esos datos por la falta de otros datos más confiables para medir las dimensiones de los fenómenos que tanto nos preocupan a todas las personas aquí presentes: quiere decir, las desigualdades, las discriminaciones y los prejuicios étnico-raciales. Reconocemos plenamente las limitaciones de los datos censales, pero durante años fueron los más adecuados que teníamos para estudiar los procesos que tanto queríamos entender.

Reconocemos también que esas desigualdades no se estructuran con base en las identidades censitarias. No creo que ningún brasileño nunca pensó ni dijo, "ah, ahí viene una persona que yo identifico como pardo, así que voy a aplicar contra esa persona las discriminaciones que corresponden

3 Marvin Harris, Patterns of Race in the Americas (New York: Walker and Company, 1964); Pierre L. van den Berghe, Race and Racism: A Comparative Perspective (New York: Wiley, 1967); Peter Wade, Race and Ethnicity in Latin America (London: Pluto Press, 1997).

4 Ver, por ejemplo, James E. Sanders, Contentious Republicans: Popular Politics, Race, and Class in Nineteenth-Century Colombia (Durham: Duke University Press, 2004); Jan Hoffman French, Legalizing Identities: Becoming Black or Indian in Brazil's Northeast (Chapel Hill: University of North Carolina Press, 2009); Matthew Restall, The Black Middle: Africans, Mayas, and Spaniards in Colonial Yucatan (Stanford: Stanford University Press, 2009). 
a una persona que yo identifico así". La discriminación es un proceso mucho más sutil, más inconsciente o semiconsciente, más rápido, más quieto. Se basa no en las identidades formales, sino en las señales, los marcos diacríticos físicos y culturales, que en su conjunto son codificados y aparentemente con más confiabilidad en Brasil que en los países hispanos por medio de las categorías raciales. Pero lo importante en ese proceso no es la categoría en sí, sino los gatillos que provocan los actos sociales de exclusión.

La gran contribución del proyecto PERLA es su enfoque en lo que es probablemente lo más importante de aquellos gatillos, el color de la piel. Analizando las consecuencias sociales de aquel dato, y combinando el color con las categorías censales, los investigadores de PERLA han tomado un paso gigantesco hacia la medición y el análisis más adecuado y más cierto de las discriminaciones y las desigualdades raciales en la región, y por ende, un paso enorme hacia la futura resolución de aquellas desigualdades. El próximo paso será la aplicación de esta metodología a los otros países de la región -espero con el mayor interés los capítulos futuros sobre Cuba y Venezuela- y la subsecuente refinación y profundización de aquella metodología. Por ahora, no me queda más nada que decir sino recomendarles este libro con el mayor entusiasmo y felicitar y agradecer a los autores de esta iniciativa pionera. 